Int. J. Electrochem. Sci., 15 (2020) 9948 - 9970

International Journal of

ELECTROCHEMICAL

SCIENCE

WWW.electrochemsci.org

\title{
Corrosion Evolution of a Concrete/Casing Steel in Simulated Formation Water under Different $\mathrm{CO}_{2}$ Partial Pressures
}

\author{
Shuliang Wang ${ }^{1,3}$, Mengjun Yao ${ }^{1}$, Xujia He ${ }^{1}$, Bensong $W u^{1}$, Li Liu ${ }^{1}$, Shidong Wang ${ }^{2,3, *}$, \\ Mingyu $\mathrm{Wu}^{3,4, *}$, Xingguo Zhang ${ }^{5}$, Dinghan Xiang ${ }^{6}$ \\ ${ }^{1}$ School of New Energy and Materials, Southwest Petroleum University, Xindu Avenue 8\#, Sichuan \\ 610500, China \\ ${ }^{2}$ Northwestern Polytechnical University, Xi'an, 710072, China \\ ${ }^{3}$ Department of Chemical and Materials Engineering, University of Alberta, Edmonton, Alberta T6G \\ 2G6, Canada \\ ${ }^{4}$ School of Materials Science and Engineering, Shanghai University, 149 Yanchang Road, Shanghai \\ 200072, China \\ ${ }^{5}$ School of Petroleum Engineering, Southwest Petroleum University, Chengdu 610500, P.R. China \\ ${ }^{6}$ Guangxi Key Laboratory of Information Materials, Guilin University of Electronic Technology, \\ Guilin 541004, PR China \\ *E-mail: shidong@ualberta.ca (S.D. Wang), mingyu8@ualberta.ca (M.Y.Wu)
}

doi: $10.20964 / 2020.10 .40$

Received: 11 June 2020 / Accepted: 1 August 2020 / Published: 31 August 2020

The corrosion behavior, mechanical properties, and microstructural evolution of a concrete/P110 casing steel system were studied in a simulated, $\mathrm{CO}_{2}$-saturated formation water under different $\mathrm{CO}_{2}$ partial pressures. It has been found that the corrosion and mechanical properties of the cement and the cement/casing interface were affected by both cement hydration and $\mathrm{CO}_{2}$ corrosion, making the performance of the cement matrix and the interfacial transition zone improve initially and then deteriorate with time. The corrosion resistance of the casing steel reduced with increasing the immersion time and $\mathrm{CO}_{2}$ pressure. The degradation of cement and cement/casing interface was aggravated under the high $\mathrm{CO}_{2}$ pressure, which assisted the formation of a defected corrosion product layer (predominantly $\mathrm{Fe}_{\mathrm{x}} \mathrm{Ca}_{1-\mathrm{x}} \mathrm{CO}_{3}$ ) and led to severer corrosion on the casing steel surface.

Keywords: Steel; $\mathrm{CO}_{2}$; Corrosion; EIS; Interfacial transition zone

\section{$\underline{\text { FULL TEXT }}$}

(C) 2020 The Authors. Published by ESG (www.electrochemsci.org). This article is an open access article distributed under the terms and conditions of the Creative Commons Attribution license (http://creativecommons.org/licenses/by/4.0/). 